\title{
Awareness toward the code of ethics among nursing students
}

\author{
Se-Won Kang \\ Dongseo University, Department of Nursing, \\ Sasang-gu, Busan, South Korea
}

\begin{abstract}
This descriptive study aimed to investigate the change in awareness toward the code of ethics for nurses among nursing students. The participants were 61 nursing students at a university in P City, South Korea. Data collection was conducted in September 2017 and March 2019. Statistical analysis was performed using mean, standard deviation, percentage, and paired samples $t$-test. Nursing students' awareness toward the code of ethics for nurses significantly improved by program year level $(t=3.284, p=0.001)$, with fourth-year scores outperforming their second-year scores in the following: "nurse and nursing clients" $(t=3.163, p=0.002)$, "obligation of nurse as experts" $(t=$ $3.268, p=0.002)$, and "nurse and cooperators" $(t=3.251, p=0.002)$. It is necessary to develop a variety of ethical education methods that use ethical codes to equip nursing students with professional ethics and morality.
\end{abstract}

Keywords: code of ethics; nursing; students; awareness

\section{INTRODUCTION}

In our modern society, biotechnology is becoming increasingly developed, and ethical issues, such as dignity, terminal care, and hospice and lifetime treatment, are occurring in the medical field; an example is the emergence of biomedical ethics related to cloning [1]. Medical professionals whose occupations deal with human life need a critical reflection of the moral and ethical aspects, as well as a process of sufficient consideration to manage life responsibly in decision-making situations related to biomedical ethics [2].

Medical professionals who deal with human life emphasize a high level of professional ethics, compared with occupations in general fields, and have codes of ethics to protect the morality of professional behavior against the responsibilities assigned by professions, not professional laws [3]. The code of ethics presents the standards for moral and ethical conduct to the members of the organization and provides clear standards for making ethical decisions or giving instructions [4-5].

The Korean Nurse Association established the Code of Ethics for Korean Nurses in 1972 [4]; its latest version is the fourth revision, introduced in 2013. The Korean Nurse Code of Ethics defines the fundamental idea of nursing as respecting and advocating human dignity and basic rights. The code of ethics of the nurse provides the basic duties of the nurse and respect for the dignity and fundamental rights of human life in relation to "nurses and nursing clients," "obligations of nurses as experts," and "nurses and cooperators" [6].

Nurses who are in charge of clinical practice in the nursing field are exposed to ethical problems. When faced with ethical conflicts and problems related to biomedical ethics, nurses need to be able to practice ethical problem-solving based on wise judgment anchored on the code of ethics. Therefore, it is necessary to form an understanding and awareness of the code of ethics for nursing students to have proper ethical values through undergraduate nursing education courses [7]. The nursing curriculum should be able to cope with various ethical 
problems faced in the nursing field by having moral, mature, ethical consciousness as well as professional knowledge [8-9].

Cross-sectional studies have examined the perception of ethics codes in Korean nursing students $[7,10]$. However, there has been no study of changes in the students' perceptions of the code of ethics.

\section{Study purpose}

This study aimed to investigate the change in awareness toward the code of ethics for nurses according to the program year level of nursing students.

\section{Study Design}

\section{METHODS}

This work is a descriptive study that investigated the change in awareness toward the code of ethics for nurses according to the year level of nursing students.

\section{Participants and data collection procedure}

The participants were 61 nursing students at a university in P City, South Korea. Primary data were collected during the first week of September (starting week of the fall semester) 2017, when the nursing students were in their second year of their undergraduate program. Secondary data were collected during the first week of March (start of the spring semester) 2019, when the nursing students were in their fourth year. The same participants were repeatedly measured in the first and second surveys.

For one year and six months from September 2017 to March 2019, nursing students completed Nursing Ethics and Professional classes (September-December 2017) and completed approximately 500 hours of clinical practice (May to December 2018). The students also completed a number of nursing major courses.

\section{Ethical considerations}

This study adhered to the ethical principles of human research. For the ethical protection of the participants, the purpose of the study was explained before the questionnaire was distributed, and the questionnaire was conducted only to those who voluntarily submitted written informed consent.

\section{Measurement}

\section{Awareness of the code of ethics}

Awareness of the code of ethics was measured using the code of ethics for Korean nurses (Korea Nurse Association, 2013) [6]. A total of 15 questions were composed. The items consisted of six questions related to "nurses and nursing clients," six questions related to "obligations of nurses as experts," and three questions related to "nurses and cooperators."

The questions on "nurses and nursing clients" were composed of items on the following: 1) delivery of equal nursing care, 2) respect for individual needs, 3) privacy protection and maintenance of confidentiality, 4) right to know and respect for self-decision making, 5) protection of vulnerable nursing clients, and 6) creation of a healthy environment.

The questions on "obligations of nurses as experts" were composed of items on the following: 1) adherence to nursing standards, 2) education and research, 3) professional activities, 4) promotion of justice and trust, 5) provision of safe nursing, and 6) maintenance of health and decency. 
The questions on "nurses and cooperators" were composed of items on the following: 1) compliance with relational ethics, 2) nursing client protection, and 3) biotechnology and dignity protection.

To measure awareness of the code of ethics, for each item, a five-point Likert scale ( $5=$ Always Aware, $1=$ Not Aware) was used. Higher scores indicated higher awareness toward the code of ethics. In a previous study [10], Cronbach's alpha, the reliability of the measuring tool, was found to be 0.927 . In the present study, Cronbach's alpha was 0.922 .

\section{Data analysis}

The collected data were analyzed using the PASW Statistics 18.0 program. Statistical analyses were performed using mean, standard deviation, percentage, and paired samples $t$-test. Statistical significance was calculated at 0.05 .

\section{RESULTS \\ Change in scores for awareness of code of ethics according to year level}

Table 1 shows the changed scores by program year level. Generally, the mean score in awareness improved in the fourth year level compared with the second $(4.20>3.84, t=3.284$, $\mathrm{p}=0.001$ ). The mean score of sub-sections significantly improved by year level as well, with the fourth-year students outperforming their second-year scores: "nurse and nursing clients" $(3.22>3.88, t=3.163, p=0.002)$, "obligation of nurse as experts" $(4.17>3.80, t=3.268 . \mathrm{p}=$ $0.002)$, "nurse and cooperators" $(4.24>3.81, t=3.251, \mathrm{p}=0.002)$. The highest improved item was "nurse standard compliance," which improved from 3.57 to 4.13 ( $\mathrm{t}=3.842, \mathrm{p}<0.001)$.

\section{DISCUSSION}

The nursing education curriculum should be structured in such a way that nursing students not only possess the intellectual capacity for nursing science but also become professionals with comprehensive education, emotional stability, and moral maturity. Undergraduate nursing courses in South Korea consist of mandatory clinical practice of 1,000 hours, nursing major courses, and extracurricular programs [11]. Clinical practice is an important educational experience for nursing students to understand the ethical issues in the medical field.

This study attempted to investigate the change in awareness of nurses' code of ethics in nursing students. The results showed that the nursing students' awareness score of the code of ethics for one year and six months increased significantly $(t=3.284, p=0.001)$.

During the eighteen-month survey interval, nursing students performed approximately 500 hours of clinical practice, completed nursing ethics and professional courses, and a number major courses. They also participated in various extracurricular programs. Therefore, the increase in the scores of awareness of the code of ethics in this study may be considered a natural result. Nonetheless, this study confirmed the degree of awareness toward the code of ethics of nursing students by the time of their graduation. The results of this study can be used as an important basis for students to set the direction of their ethics education before graduation for the remaining undergraduate courses. Notably, the scores of items 'education and research' of 'obligations of nurse s experts' section was low, and the score improvement was likewise low. Before graduation, the lack of it must be supplemented.

The present authors entirely agree with the suggestion of using the code of ethics to educate nursing ethics that can be applied in practice [12]. The code of ethics will provide guidance for the ethical practice among clinical nurses and nursing students. Ethics education requires repeated instruction, and it is necessary to ensure that improved awareness of the Code of 
Ethics is maintained. After graduation, nursing students will have the ability to deal with various medical ethical issues as professional health care professionals.

\section{Limitations of the study}

This study was conducted in university nursing students. As such, it is necessary to take caution in the generalization and interpretation of the study results.

\section{CONCLUSION}

In this study, nursing students' awareness toward of the code of ethics for nurses was significantly improved from their second year to their fourth year in the program. It is necessary to develop a variety of ethical education methods that use ethical codes to enable nursing students to be equipped with professional ethics and morality.

\section{References}

Moon, M. Y., Jeon, M. K., and Jeong, A. W. Relationship between nurse' consciousness of biomedical ethics, job satisfaction and nursing performance. Journal of Korean Bioethics Association, 2013. 14(1): p. 27-47.

Lee, K. J., Lee, E., and Park, Y. S. Comparison on influencing factors on consciousness of biomedical ethics in nursing students and general students. Journal of Digital Convergence, 2016. 14(12): p. 377-388.

Epstein, B. and Turner, M. The nursing code of ethics: its value, its history. Online Journal of Issues Nursing, 2016. 20(2): p. 4 .

Han, S. S., Ahn, S. H., Kim, H. G., Kim, Y. S., Cho, G. C., Lee, W. H., Lee, G. S. and Kim, K. K. The process of the third amendment of the Korean nurses' code of ethics. Korea Nursing, 2006. 44(3): p. 63-81.

Kim, Y. S., Kang, S. W. and Ahn, J. A. Moral sensitivity on the application of code of ethics. Nursing Ethics, 2013. 20(4): p. 470-478.

Korea Nurse Association. Korea nurse ethics, Retrieved from https://www.koreanurse.or.kr/about_KNA/ethics.php?mn=2\#s1 (accessed February 2019).

Jeong, G. S. The influencing factor of consciousness of biomedical ethics, moral sensitivity and critical thinking disposition on the code of nurse ethics of nursing student. Journal of the Korea Academia-Industrial cooperation Society, 2017. 18(11): p. 544-555.

Numminen, O. H., van der Arend, A., and Leino-Kilpi, H. Nurse educators' and nursing students' perspectives on teaching codes of ethics. Nursing Ethics, 2009. 16(1): p. 69-82.

Monrouxe, L. V., Rees, C. E., Dennis, I. and Wells, S. E. Professionalism dilemmas, moral distress and the healthcare student: insights from two online UK-wide questionnaire studies. BMJ Open, 2015. 5(5): p. e007518.

Kang, S. W., Choi, E. J. Awareness towards code of ethics for Korean nurses and nursing professionalism among nursing students. Journal of the Korean Data Analysis Society, 2015. 17(2): p. 1101-1114.

Korean Accreditation Board of Nursing Education. Nursing education accreditation," Retrieved from http://kabon.or.kr/eng/. Accessed February 09, 2019.

Vanlaere, L. and Gastmans, C. Ethics in nursing education: learning to reflect on care practices. Nursing Ethics, 2007. 14(6): p. 758-66. 
Table 1 The score changes of awareness towards code of ethics by grade

\begin{tabular}{|c|c|c|c|c|}
\hline \multirow[t]{2}{*}{ Variables } & $\begin{array}{l}\text { Second grade } \\
\text { (sophomore) }\end{array}$ & $\begin{array}{l}\text { Fourth } \\
\text { grade } \\
\text { (senior) }\end{array}$ & differences & \multirow[t]{2}{*}{$\mathrm{t}(p)$} \\
\hline & Mean(SD) & Mean(SD) & Mean(SD) & \\
\hline Total mean scores of awareness towards code of ethics & $3.84(0.58)$ & $4.20(0.55)$ & $0.36(0.84)$ & $3.284(0.001)$ \\
\hline Nurse and nursing clients & $3.88(0.55)$ & $4.22(0.55)$ & $0.33(0.82)$ & $3.163(0.002)$ \\
\hline $\begin{array}{l}\text { 1. Provision of nursing care without discrimination: } \\
\text { Nurses should provide care without } \\
\text { discrimination, regardless of nationality, race, } \\
\text { religion, ideology, age, sex, political, social, or } \\
\text { economic status, sexual orientation, type and } \\
\text { degree of disease and disability, and cultural } \\
\text { differences of nursing clients. }\end{array}$ & $4.11(0.77)$ & $4.16(0.77)$ & $0.04(1.20)$ & $0.319(0.751)$ \\
\hline $\begin{array}{l}\text { 2. Respect for individual needs: Nurses should } \\
\text { provide care with respect for personal needs } \\
\text { based on customs, beliefs, and values of nursing } \\
\text { clients. }\end{array}$ & $3.67(0.76)$ & $4.13(0.69)$ & $0.44(0.99)$ & $3.292(0.002)$ \\
\hline $\begin{array}{l}\text { 3. Respect for patients' privacy and confidentiality: } \\
\text { Nurses should protect the privacy of nursing } \\
\text { clients, maintain confidentiality, and only share } \\
\text { information necessary for nursing. }\end{array}$ & $4.39(0.66)$ & $4.49(0.69)$ & $0.09(1.02)$ & $0.747(0.458)$ \\
\hline $\begin{array}{l}\text { 4. Respect for patients' right to know and self- } \\
\text { decision making: Nurses should involve nursing } \\
\text { clients in the whole process of nursing and } \\
\text { provide sufficient information and explanations } \\
\text { to help nursing clients make their own decisions. }\end{array}$ & $3.96(0.75)$ & $4.29(0.69)$ & $0.32(1.10)$ & $2.315(0.024)$ \\
\hline $\begin{array}{l}\text { 5. Protection of vulnerable patients: Nurses should } \\
\text { provide protection and care to nursing clients } \\
\text { facing vulnerable environments. }\end{array}$ & $3.68(0.74)$ & $4.22(0.80)$ & $0.54(1.14)$ & $3.679(0.001)$ \\
\hline $\begin{array}{l}\text { 6. Creation of a healthy environment: Nurses should } \\
\text { participate in the protection of nursing clients } \\
\text { from harmful social environments, disasters, and } \\
\text { ecological contamination that threaten health, } \\
\text { and in the preservation and maintenance of a } \\
\text { healthy environment. }\end{array}$ & $3.49(0.95)$ & $4.03(0.77)$ & $0.54(1.19)$ & $3.547(0.001)$ \\
\hline Obligations of nurse as experts & $3.80(0.66)$ & $4.17(0.60)$ & $0.36(0.88)$ & $3.268(0.002)$ \\
\hline $\begin{array}{l}\text { 7. Nursing standards compliance: Nurses should } \\
\text { always work in accordance with the operation } \\
\text { standards of the Korea Nursing Association and } \\
\text { be responsible for judging and acting in } \\
\text { connection with nursing. }\end{array}$ & $3.57(0.93)$ & $4.13(0.76)$ & $0.55(1.13)$ & $3.842(<0.001)$ \\
\hline $\begin{array}{l}\text { 8. Education and research: Nurses should } \\
\text { participate in education and training for } \\
\text { improvement of nursing ability and evidence- } \\
\text { based practice, and contribute to the } \\
\text { development and research of nursing standards. }\end{array}$ & $3.86(0.76)$ & $3.95(0.90)$ & $0.08(1.17)$ & $0.546(0.587)$ \\
\hline $\begin{array}{l}\text { 9. Professional activity: Nurses should participate in } \\
\text { the improvement and development of nursing } \\
\text { policies and related systems through professional } \\
\text { activities. }\end{array}$ & 3.67 (1.07) & $4.01(0.90)$ & $0.34(1.31)$ & $2.045(0.045)$ \\
\hline 10. Promotion of justice and trust: Nurses should & $3.83(0.87)$ & $4.24(0.74)$ & $0.40(1.18)$ & $2.693(0.009)$ \\
\hline
\end{tabular}
maintain equality and fairness in the distribution of medical resources and nursing activities, and participate in the promotion of common good and 
trust in the society.

11. Provision of safe nursing care: Nurses should take

$4.09(0.74)$

$4.49(0.67)$

$0.39(0.98)$

$3.111(0.003)$

human dignity, values, and personal safety as a

priority throughout the whole process of nursing

and take actions to minimize risks.

12. Maintenance of health and dignity: Nurses should protect their own health and maintain their pride and decency as professionals.

\begin{tabular}{|c|c|c|c|c|}
\hline Nurses and cooperators & $3.81(0.70)$ & $4.24(0.68)$ & $0.42(1.01)$ & $3.251(0.002)$ \\
\hline $\begin{array}{l}\text { 13. Respect of relational ethics: Nurses should } \\
\text { perform ethical obligations for nursing clients and } \\
\text { society when working with professionals and } \\
\text { employees of industries related to medicine. }\end{array}$ & 3.57 (0.93) & $4.11(0.81)$ & $0.54(1.31)$ & $3.223(0.002)$ \\
\hline $\begin{array}{l}\text { 14. Protection of patients: Nurses should take } \\
\text { adequate actions in situations where the health } \\
\text { and safety of nursing clients are threatened. }\end{array}$ & $4.13(0.69)$ & $4.37(0.68)$ & $0.24(1.01)$ & $1.900(0.062)$ \\
\hline $\begin{array}{l}\text { 15. Protection of life, science and technology, and } \\
\text { dignity of patients: Nurses should protect the } \\
\text { dignity of human life and nursing clients from } \\
\text { biotechnology-based procedures that are not safe. }\end{array}$ & $3.75(0.90)$ & $4.22(0.86)$ & $0.47(1.24)$ & $2.979(0.004)$ \\
\hline
\end{tabular}

